\title{
New opportunities for the redesign of agricultural and food systems
}

\author{
Jules Pretty ${ }^{1}$ \\ Accepted: 19 April 2020 / Published online: 18 May 2020 \\ (c) Springer Nature B.V. 2020
}

Keywords COVID-19 · Coronavirus

This much we know: the whole world changed in 2020. This virus has made us consider afresh our own lives and relations with other people, our own consumption patterns, our access to natural places, and above all our health. Slow trends will speed up, some for the greater good, some not. We might come to think this was a rehearsal for how economies could be shattered by a climate crisis. One thing has become very clear: when faced with existential threat, we put our value on those working for the public good. Individuals working alone or for themselves will not be able to mitigate or solve this pandemic and its ripple effects. Could this open up a space for more collective and socially-oriented action in agricultural and food systems? And might the planet and our economies come out of this better placed to produce sustainable, equitable and healthy systems for all people?

For as long as people and cultures have managed natural resources, collective action has produced systems of efficient and effective offtake as well as sustaining natural capital and valued flows of ecosystem services. A wide range of different types of more sustainable agriculture have recently been developed and implemented, most centring on the notion that making more of existing land by sustainable intensification and collective action can result in synergistic coproduction of food and ecosystem services. Yet at the same time, agriculture is still contributing to biodiversity loss, nutrient loading of the biosphere, climate forcing, depletion of aquifers and surface water, and pollution of air, soil and water (Rockström et al. 2017).

We undertook a 2018 global assessment of sustainable intensification (Pretty et al. 2018) to show that systems of

This article is part of the Topical Collection: Agriculture, Food \& Covid-19.

\section{Jules Pretty}

jpretty@essex.ac.uk

1 School of Life Sciences, University of Essex, Colchester, UK agricultural management now require fresh redesign if they are to sustain beneficial outcomes over long periods of time across differing ecological, economic, social and political landscapes. Redesign is a social and institutional challenge, as landscape-scale changes are needed for positive contributions to biodiversity, water quantity and quality, pest management and climate change mitigation. Three non-linear stages were identified: efficiency, substitution and redesign (Hill 1985; Pretty 2018).

Efficiency aims to make better use of on-farm and imported resources within existing farm configurations. Many agricultural systems are wasteful, and so on-farm efficiency gains can arise from better management to reduce use, precision targeting of fertiliser, pesticide and water to cause less damage to natural capital and human health.

Substitution focuses on the replacement of technologies and practices with more sustainable forms. Forms of substitution include the release of biological control agents to substitute for agrochemical inputs, replacing the use of soil by hydroponics, and no-tillage systems that use new forms of direct seeding and weed management to replace inversion ploughing.

Redesign is the stage fundamental for achieving sustainability at geographic scale. Redesign of agroecosystems and landscapes is necessary to harness ecological processes such as predation, parasitism, allelopathy, herbivory, nitrogen fixation and pollination. While efficiency and substitution tend to be incremental within current production systems, redesign should be the most transformative, often resulting in fundamental changes to system components and configurations.

Yet redesign also requires protection and expansion of social capital and the capacity for continuing co-production of ecologically and socially viable technologies and practices. Social capital increases trust, reciprocity and mutual obligations, and creates norms that guide behaviours. We have recently also undertaken a global assessment of 
intentionally-formed social capital manifested as collaborative groups within specific geographic areas. This focused on collective action for integrated pest management, joint forest management, watersheds and land, water sharing, microfinance, and innovation platforms. The number of groups worldwide has grown from $0.5 \mathrm{M}$ at about 2001-03 to $8.5 \mathrm{M}$ (2018) across 55 countries. Farmers and land managers working together with scientists and extensionists in these forms of social infrastructure have improved natural capital and agricultural productivity.

The overwhelming evidence from the field and reported in the published literature is that collective management of resources leads to redesign and net increases in system productivity. There have been few counterfactual examples, such as where groups could have been formed to increase resource exploitation or extraction (e.g. water or forest capture). There are of course also many other institutions, corporations and groups of individuals actively engaged in resource depletion to serve private and generally short-term interests.

This global platform of more than $8 \mathrm{M}$ social groups comprising $3 \%$ of the world population is an opportunity to consider greater challenges: if we are now to bring forth different worlds as a function of a quest to transform the way we live, we will need to modify the epistemes that have come to dominate modern consumption cultures (Bawden 2011). Some of this social capital will be influencing global systems, resulting for example in mitigations of climate change, biodiversity loss and air pollution, as well as increases in net food production. Platforms of groups, for example, could engage in co-production of new patterns of material consumption and ways of living within global boundaries and limits.

The term sustainable suggests an incorporation of the need for improvement (e.g. to well-being, food production, natural capital), and thus requires the need to change the way we as individuals think about and come to know about the world. Sustainability is a form of progressive and gradual change that requires changes in behaviours and practices as well as internal changes to mindsets. It could be that novel forms of social capital can open up science to innovation, particularly where problems are complex and solutions unknown, and where the values of all actors are salient.

Substantial advances have been made in recent years to improve the sustainability of agricultural and food systems. The silent revolution of social capital manifested as groups has created platforms capable of landscape- and economy-wide redesign. It is conceivable that the COVID crisis will speed up these socially-just outcomes more than had recently been envisaged.

\section{References}

Bawden, R.J. 2011. Epistemic aspects of social ecological conflict. In Social Ecology: Applying Ecological Understandings to Our Lives and Our Planet, ed. D. Wright, C. Camden-Pratt, and S. Hill. Glos: Hawthorn Press.

Hill, S. 1985. Redesigning the food system for sustainability. Alternatives 12: 32-36.

Pretty J, Benton T G, Bharucha Z P, Dicks L, Butler Flora C, Hartley S, Lampkin N, Morris C, Pierzynski G, Prasad P V V, Reganold J, Rockström J, Smith P, Thorne P, Wratten S. 2108. Global assessment of agricultural system redesign for sustainable intensification. Nature Sustainability 1: 441-446.

Pretty J. 2018. Intensification for redesigned and sustainable agricultural systems. Science 362: eaav0294

Rockström, J., J. Williams, G. Daily, A. Noble, N. Matthews, L. Gordon, H. Wetterstrand, F. DeClerck, M. Shah, P. Steduto, C. Fraiture, N. Hatibu, O. Unver, J. Bird, L. Sibanda, and J. Smith. 2017. Sustainable intensification of agriculture for human prosperity and global sustainability. Ambio 46: 4-17.

Publisher's Note Springer Nature remains neutral with regard to jurisdictional claims in published maps and institutional affiliations.

Jules Pretty is Professor of Environment \& Society at the University of Essex. His sole-authored books include The East Country (2017), The Edge of Extinction (2014), This Luminous Coast (2011, 2014), The Earth Only Endures (2007), Agri-Culture (2002) and Regenerating Agriculture (1995). He is a Principal Fellow of the Higher Education Academy, Fellow of the Royal Society of Biology and the Royal Society of Arts, former Deputy-Chair of the government's Advisory Committee on Releases to the Environment, and has served on advisory committees for BBSRC and the Royal Society. He was presenter of the 1999 BBC Radio 4 series Ploughing Eden, a contributor and writer for the 2001 BBC TV Correspondent programme The Magic Bean, and a panellist in 2007 for Radio 4's The Moral Maze. He received a 1997 award from the Indian Ecological Society, was appointed A D White Professor-at-Large by Cornell University from 2001, and is Chief \& Founding Editor of the International Journal of Agricultural Sustainability. He received an OBE in 2006 for services to sustainable agriculture, an honorary degree from Ohio State University in 2009, and the British Science Association Presidential Medal (Agriculture and Food) in 2015. He is currently a trustee for WWF-UK and the Green Light Trust. This Luminous Coast was winner of New Angle Prize for Literature in 2013, and The East Country was winner of the East Anglian book of the year in 2018. He is among the top $1 \%$ most cited scientists in the world. 